\title{
LIMITS OF DISCOURSE: EXAMPLES FROM POLITICAL, ACADEMIC, AND HUMAN-AGENT INTERACTION ${ }^{1}$
}

\author{
Josef Schmied
}

\begin{abstract}
This contribution looks at modern discourse from two perspectives. It tries to show that the term 'discourse' has been expanded over the last few decades to include more phenomena and more disciplines that use it as a basis for their analyses. But it also tries to show that discourse in the sense of effective interaction has met its limits. The fundamental question is: When is discourse real discourse, i.e. more than a series of unrelated utterances and when is it coherent interactive communication? This paper does not intend to provide a new overall theoretical-methodological model, it uses examples from political discourse to demonstrate that popular discourse is often unfortunately less interactive than seems necessary, examples from academic discourse to illustrate that community conventions are being standardised more and more, and from humanoid-human discourse to argue that it is still difficult to construct agents that are recognised as discourse partners by human beings. Theoretical approaches to discuss these limits of discourse include coherence and intentionality. They can be applied to show where lack of cohesion in discourse indicates lack of cohesion in society.
\end{abstract}

\section{Keywords}

discourse, interaction, political discourse, academic discourse, human-agent discourse, intentionality, cohesion

\section{Introduction}

As a contribution to the Special Issue on Specialised Discourse in Discourse and Interaction, it may be appropriate to look at current examples of discourse practices in our modern technological world. The term 'discourse' has become extremely popular in academia over the last few decades at the expense of 'communication' or 'text'. Whereas communication seems to focus on the effect of a text on listeners or readers and text on the product, discourse focuses on the interaction.

\subsection{Recent expansions from the original meanings of 'discourse'}

To go back to the original meanings of 'discourse' (and address the wherefrom part of the Special Issue title), I checked the OED online (s.v.) and found that although the term has been part of the English language for almost 600 years, many meanings are marked as Obsolete or Now rare. Only meanings 
6 "interaction" and 7 "body of statements" seem to be in line with the linguistic definition in 8 "connected series of utterances ... forming a unit for analysis" and, to judge from the quotations, the former sense is much older than the latter:

6. Interaction, dealings, communication.

Apparently rare before $20^{\text {th }}$ cent.; in quot. 1603 perhaps with the narrower sense 'familiar intercourse, familiarity'. 1603 - 2005

7. The body of statements, analysis, opinions, etc., relating to a particular domain of intellectual or social activity, esp. as characterized by recurring themes, concepts, or values; (also) the set of shared beliefs, values, etc., implied or expressed by this. Frequently with of or modifying word. 1931-2006

8. Linguistics. Aconnected series of utterances by which meaning is communicated, esp. one forming a unit for analysis; spoken or written communication regarded as consisting of such utterances.

The sense evolution recorded in the reference dictionary is reflective of some of the current social perspectives on discourse (cf. 1.2). However, a look at occurrences of discourse in contemporary corpus data (cf. 1.3) also helps throw light on how diffuse the term is and what meanings it has come to take.

It is interesting that discourse is presented in a similar historical development as conversation in the OED (s.v.). Meaning 7 of conversation contains the collocation familiar discourse or talk with the same discourse meaning of 'interaction' as in sense 6 of discourse and, again to judge from the quotation dates, a similarly long history:

7a. Interchange of thoughts and words; familiar discourse or talk. $1586-1871$

b. 'A particular act of discoursing upon any subject' (Johnson); a talk, colloquy. $1694-1871$

c. to make conversation: to converse for the sake of conversing; to engage in small talk.

When we check the meanings of 'discourse' in the standard modern dictionaries, we notice that they do not add much to the discussion: the online American Merriam-Webster confirms the etymology and defines it (s.v.) as "verbal interchange of ideas, especially conversation", but also "a mode of organizing knowledge, ideas, or experience", which is directly linked to "critical discourse', while the online learner dictionaries (like Longman) distinguish between uncountable and countable meanings. 


\subsection{Changing specialised academic discourses on 'discourse'}

If we see specialised discourse as the interplay of textlinguistic and cultural factors in the construction of professional discourse, the interaction depends on the functional needs within specialised domains as well as across wider academic contexts. Of course, all specialised discourse must be learnt, it has no native speakers. Discipline-specific texts as reading material and corpus collections as reference are necessary (Lee \& Swales 2006). And this long learning process must create a tension and a possible limit, especially for the non-specialist or specialist in another discipline or academic discourse community. Thus, such discourses are increasingly seen as disparate and non-specialists perceive their limits. However, there is a difference whether discourse partners aim at construing the language so that interaction is easy or difficult or even impossible for others.

In Halliday's terms (e.g. Halliday \& Matthiessen 1999), the interpersonal metafunction "is concerned with enacting interpersonal relations through language, with the adoption and assignment of speech roles, with the negotiation of attitudes, and so on - it is language in the praxis of intersubjectivity, as a resource for interacting with others" (Halliday \& Matthiessen 1999: 7).

Discourse analysis is sometimes defined as the study of language above the level of a sentence, of the ways sentences combine to create meaning, coherence, and accomplish purposes. But the local coherence we know from Halliday and Hasan (1976) seems not enough, if we follow Unger (2006: 27, 34):

Samet and Schank conclude that the connectivity of discourse is not just a matter of intersentential links, but must also involve connectivity relations between the main events of the text (what one might call global coherence relations)....

I conclude that it is not to other kinds of relations, or relations on different levels, that we must turn, but to another kind of explanation of what makes a text 'hang together' and 'make sense.' The relevance-theoretic framework fulfils this condition. In this framework, the main functions of the concept of global coherence (ruling out 'mock narratives') are fulfilled by the notion of relevance itself.

In contemporary systemic functional grammar, the societal basis of discourse can be interpreted like this: Sequences impose a certain order on our experience in terms of the relations that connect one happening with another. Hence sequences can be used to store information about the world in the form of organized text 'this is how to change tyres on your car', 'this is how to make cauliflower surprise', etc. Such texts often fall into a clearly recognizable text type, such as procedures, proofs, explanations, and episodic narratives. Not all texts are as highly regulated as these; but it is usually possible to make some prediction 
about the kinds of sequence, and the complexity to which sequences extend, in most of our culturally recognized modes of discourse (Halliday \& Matthiessen 1999: 122). In a recent introduction to discourse studies, Renkema and Schubert (2018: 55) "wonder" provocatively:

Discourse has many different manifestations in many different situations, from chat to deed of purchase, from sermon to shopping list. These manifestations are so different that one may wonder if the term discourse is perhaps too vague to span all differences.

Thus, it is safe to say that discourse is a contested term rooted in different disciplines and used in a variety of ways. In a narrow sense, discourse can be understood as language in use - everyday ways of talking - what James Gee in his book Social linguistics and literacies: Ideology in Discourses (1990) refers to as 'little d' discourse. In a broader sense, it can be used to refer to a system of language use and other meaning-making practices (e.g. behaviour, dress, and customary practices/habits) that form ways of talking about social reality what Gee refers to as 'big D' Discourse (also see "Discourse" in Glossary of Multimodal Terms, n.d.). In a contemporary sociological perspective of discourse, this reads like this:

It is also worth noting that discourses, as defined above, are always ideological and 'positioned' ways of presenting social practices in the world and life in general, which means that they are not casual, but always come from somewhere. For example, political parties and political organisations often produce and reproduce particular discourses about events and phenomena which are deemed important by society in general: a preferred discourse of education where there is public debate about declining standards, or a preferred discourse produced by representatives of a government keen to convince the public that the economy is going well. (Block 2019: 10)

This quote brings in the notion of 'discourse community', or the users' sets of values and ideologies, a notion reflected in the OED definition $\mathrm{n} .7$ above and a relevant one to explore where specialised discourse is going and how it must be construed to be perceived as effective or even harmonious.

\subsection{Current usage in the News-On-the-Web (NOW) Corpus}

If we want to follow up the actual current usage of the term discourse, modern web-as-corpus methodologies provide interesting opportunities. When we look at the frequency of the term discourse in the BYU Corpora (Davies 
2016), we notice a steady increase over the last one hundred years (in the Corpus of Historical American English (COHA)) and a stably high figure over the last ten years (esp. in the News-On-the-Web (NOW) Corpus). In the collocations (Figure 1), we recognise the dominance of 'political' discourse, including public or national. The collocates intellectual and academic are less important in this database. It is also interesting that media discourse is not (yet?) prominent in the NOW Corpus. And still, in particular social media have made a dramatic impact on the political discourse over the last few years with the growing concern about hate speech and fake news (Schmied 2012, 2017), especially in the discourse on Twitter and Facebook.

\begin{tabular}{|c|c|c|c|c|c|c|}
\hline Beur & $\mathbf{a}$ & contus & into & Nii. & 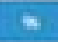 & 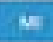 \\
\hline 1 & 口 & Ruauc & 13104 & sarcoos & 0.22 & 312 \\
\hline$z$ & $\square$ & Poviras & tras & 300064 & axs & 3.60 \\
\hline 3 & 0 & MEstiner & 908 & ceosest & $e n$ & 586 \\
\hline 4 & 0 & casent & Sil & inser & 0.25 & 94 \\
\hline 5 & $\square$ & onteows & 2301 & 50005 & Q.se & 728 \\
\hline 5 & 0 & turnenkt. & ont & sences & 097 & 15 \\
\hline 7 & $\mathrm{C}$ & ent & $20 \%$ & 1stioot & a.s & 461 \\
\hline 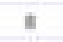 & 0 & trvt & $22 n$ & $20 s+a 2 x$ & Des & 10 \\
\hline$\Leftrightarrow$ & $\square$ & contabution & 9ss & seans & 6.25 & 134 \\
\hline to & C & simaterual & $n \infty 6$ & $20006 y$ & a.44 & 693 \\
\hline$\pi$ & 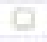 & HATON & $m$ & isatens & est & $x+2$ \\
\hline 12 & 0 & mostrant & aso & 220000 & 037 & 34 \\
\hline
\end{tabular}

Figure 1: The collocates of 'discourse' in the News-On-the-Web (NOW) Corpus

When we look at the usage (Figure 2) in the BYU Word and Phrase Info (based on the Corpus of Contemporary American English (COCA)), we see that discourse is clearly an academic word and related to two groups of genres, dialogue and dissertation. These recall the OED dictionary entry (meanings 6 'interaction' and 7 'body of statements, analyses and opinions... related to a particular domain, intellectual or social activity') and are also found in the "Wordnet" definitions 1 and 2 in Figure 2: discourse is the most frequent in the dialogue class and an important member of the dissertation class (on the left). The collocates list and the sample sentences confirm this usage (on the right). 


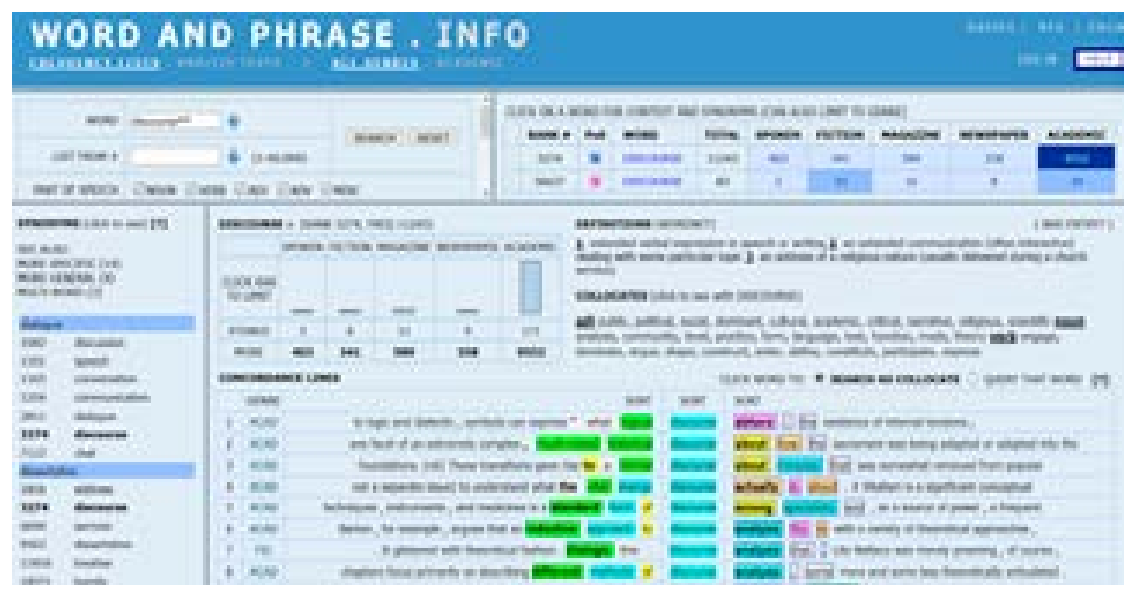

Figure 2: "Discourse" in the BYU 'info', based on the Corpus of Contemporary American (COCA)

The dynamic development of 'discourse' over the last thirty years can be seen in the increase of computer-mediated communication. Basically all discourse is digital today: personal letters were replaced by email, printed by online newspapers, encyclopaedias by Wikipedia (even the Britannica is only available online today), company circulars have turned into Twitter messages (Darics 2015), etc. It is interesting that this digitalisation of discourse has occasionally made the interactive meaning component of 'discourse' more clearly visible (e.g. comments can be linked more directly to the electronic article today than in traditional letters-to-the-editor and up-dates can be made more easily and more easily traceable in Wikipedia than in traditional encyclopaedias), but it has also increased the dangers of losing track of the interaction (e.g. within the comments under a newspaper article or within Twitter tweets). This calls for a new, strict definition of the concept of 'discourse'.

\subsection{A new linguistic definition of discourse based on increasing awareness of limits of good discourse and explicit discourse cohesion}

For the purposes of this paper on the limits of discourse, I propose a narrow linguistic definition of (good) discourse to set it apart from the many cases where discourse was more related to discord than to communication and dialogue in a positive sense. I see 'discourse' as primarily verbal (but multimodal) interaction between humans (increasingly using digital tools and media) (ideally) based 
on human cooperation, understanding and responsibility. I will then show the limits of discourse, which could also be called 'discord discourse', because the coherence is not made explicit (enough) or not even intended, because writers do not want to engage with their discourse partners. I try to exemplify this by looking at three different discourse types and ask critical questions:

1) Can we see fake news and many other non-communicative social media interaction as effective discourse?

2) Can we analyse academic discourse as understanding conventions that make readers feel 'at ease"? '

3) Can we regard computer generated, humanoid-human discourse as credible discourse in academic settings?

4) Can we find functional linguistic concepts that can be used to signal mutual effort to interactive, coherent discourse?

Whereas the first question refers to wrong or no intentions of construing effective discourse, the second refers to insufficient conventional construal of effective discourse, the third to the insufficient explicit construal of effective discourse and the final question focuses on the linguistic contribution in this new definition of 'discourse'.

\section{Social media and flouting of discourses}

Today's ubiquitous social media discourse can be seen as a special case of computer-mediated communication (CMC, cf. Herring 1996). What was seen as a special advantage of $\mathrm{CMC}$, that it can be free from disturbing influences and physical context, can also be seen as its major disadvantage now, when all bonds of social behaviour may be lost and CMC can shape anti-social behaviour and online conflict. CMC today is an interesting multimodal discourse, where conventionalized cues, like images, symbols, memes, even animations provide a seemingly endless reservoir for anti-social behaviour, which also makes it so difficult to define the limits of free speech and to counter hate speech in the social media automatically.

\section{1 'Discourse' in social media like Twitter}

Discourse approaches have been used to analyse social media posts or tweets. In particular "negatively marked online behaviour", like flaming and trolling (e.g. Hardaker 2017), has been discussed for about 20 years (cf. Jucker \& Taavitsainen 2000), but it has only been perceived as an online epidemic since the international use of Facebook and Twitter. Now 'cyberstalking' and 'disruptive discourse' have to be analysed in terms of impoliteness or even 
hostility (cf. Culpeper 1996). The following three examples illustrate the phenomenon of 'limits of discourse', because the messages are obviously not intended for interaction, but as a 'discord discourse':

(1) Trump's October surprise will be the announcement of "his infection." Fake, but quite dramatic. This twist will blow Biden off the screens, the "Trump COVID watch" dominating every minute of every day. Then, 14 days later, Trump will emerge, 100\% cured by hydroxychloroquine. (@JohnCammo 18.09.2020, accessed 02.10.2020)

(2) "twitter: noooo you cannot make fun of supreme court lady dying that is so mean!!!!!! also twitter: haha orange man get corona coof hope he dies lol" (@JohnSwanYT 02.10.2020, accessed 02.10.2020)

"Cancel culture is stupid but Bill Maher reallyyyyy needs to get canceled" (@seltbra28.09.2020, accessed 02.10.2020)

The first satiric post has been retweeted as a prophetic statement about President Trump's COVID infection. It is part of a conspiracy theory that the contamination is fake and planned to support his campaign. The tweet also ironises another controversy around the treatment hydroxychloroquine, but in this heated discourse atmosphere, irony is never a good cooperative discourse strategy. It rather terminates and accentuates a point than continuing the argumentation.

The second tweet mirrors and ironises discrepant internet discourses on death and disease. The casual style, oral tone and the missing definite articles are in stark contrast to the serious topic. It purposefully does not name the persons but shows the hypocrisy in the different treatments of "supreme court lady" and "orange man". The recently trending term Schadenfreude [gloat] around Trump's illness is evidence of the active discussion on hate discourse online.

The third tweet is just another example of the many heated debates on cancel culture. Cancel culture, the practice of holding celebrities accountable for their wrong deeds or even ascribed attitudes and dismissing them from society through hate and disapproval, has been at the centre of social debate lately. Some perceive it as mobbing and are willing to give the cancelled subjects a chance for repentance, while others find it fair to reject individuals from society due to their wrong actions. 

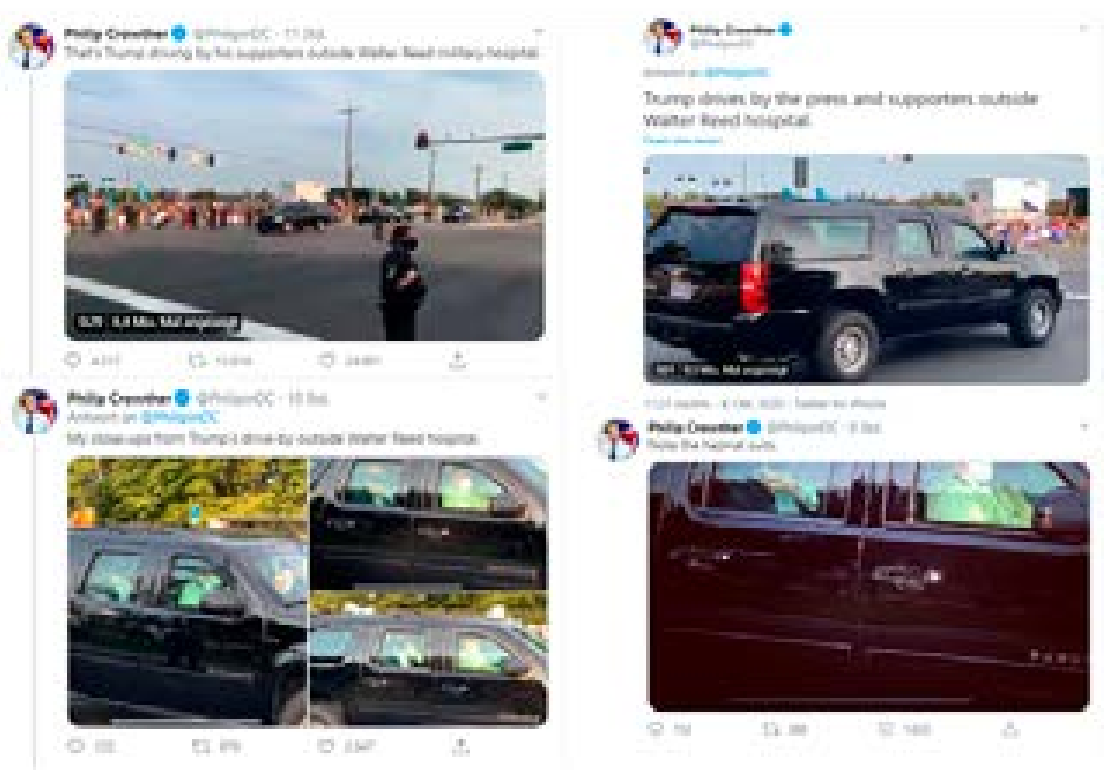

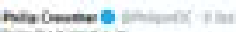

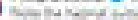

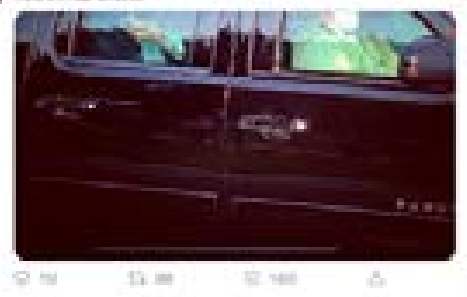

Figure 3: Main tweet by Philip Crowther (journalist for the Associated Press) reporting on Trump's short excursion from the hospital greeting his supporters

Even more complex is Figure 3, not only because it is a multimodal documentation. The main tweet by journalist Philip Crowther objectively reports about Trump leaving the hospital for a few minutes, where he was treated for his COVID infection, greeting his supporters on the street. The replies following this tweet in Figure 4 look like a discourse, when in fact it is rather a sequence of monologues related to the same topic, but without direct reference and directed coherence to the preceding main tweet. They can be thus regarded as a discourse/text colony, i.e. a discourse whose adjacent components do not form continuous prose and may be used separately without referring to others (cf. Dontcheva-Navratilova 2009: 51). 


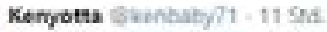

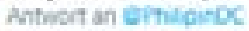

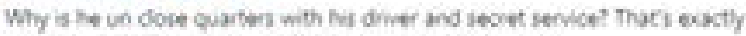
why I don t bolieve he kas it. Pelical stunt tabie tor ane.
Q 6
2. $\pi$
Q $\mathrm{Xn}$

It.

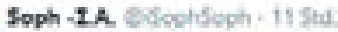

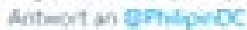

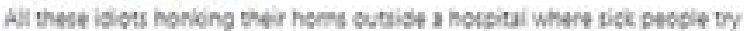
to slewe bod deal with thwir poin covid only be his supvorters. No

compassienate pansen wolld twer as that.

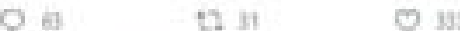

4.

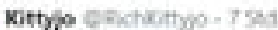

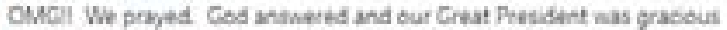

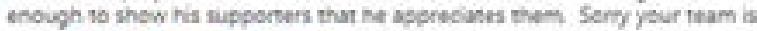

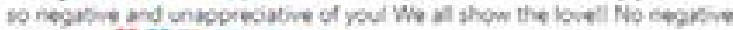

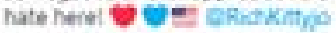

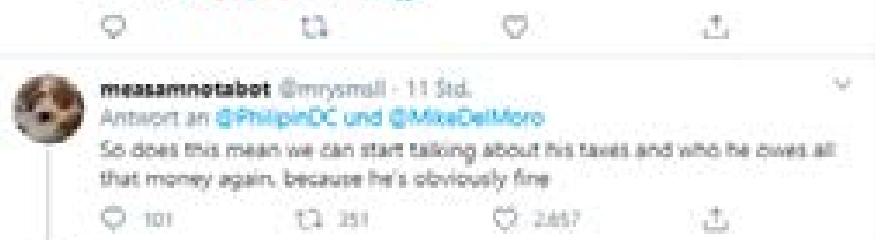

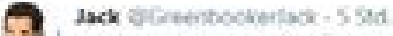

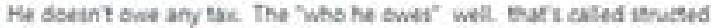
debt. if yeu would see me 10 seach yeu about in I tan.

Q 21

ManaMana Ghuta21023 - 11 Yod

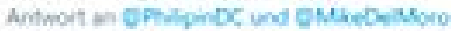

Her risks the healh of erwybody in the car. He has net learned a thing
Q 181
ta. 12
C. 1 ix

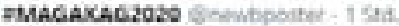

Oochn so the masies and PFE DOWT work now and law enforcoment pocd? Im getting so contured how often the lett clanges nurnower. Lart weve, or was it yestendby everyone war being lactired sor not wearing makes becave mask protect people and law enforcement was bad Get it. Q

17

I.

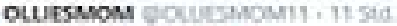

Antwert an CPAlipindDC

And heli be released tomonow fim beginning to think this entive thing is a enged event
Q 70
t?. $10 \mathrm{a}$
(7) 12

Figure 4: Replies to the main tweet 
The crucial point is that although the 'discourse' is all on the US president, the focus is always so different that the local coherence is completely lost: first, user Kenyotta believes that Trump's COVID infection is made up because for the user it is simply unthinkable that an infected person would knowingly sit in a car and risk other's lives. The thread continues with obviously insulting thoughts about other patients in the hospital who are disturbed in their healing processes by "idiots honking their horns" supporting the US President. Kittyjo, apparently a Trump supporter, turns the insult into a rather positive reply by bringing up her religious beliefs and prayers for the US President. The following replies refer directly to the main tweet by Philip Crowther and shift the focus of their discourses again. Although the main discourse is still about Trump, users measamnotabot and Jack shift to his alleged tax fraud because he seems to be cured and people should go back to normalcy by talking about the real issues that were discussed before Trump's infection. The preceding replies by ManaMana and \#MAGAKAG2020 refer back to the original main tweet, whereas the first reply accuses Trump of knowingly infecting his Secret Service agents and the latter one drawing the conclusion that ManaMana is a left-wing supporter who constantly change their narrative about their opinion on law enforcement and whether masks prevent the uncontrollable spread of the virus. Although user ManaMana may not have intended any of these presuppositions, the original discourse is once again disrupted and shows how deeply divided this nation really is. The last reply by OLLIESMOM is similar to the first one by Kenyotta displaying a clear disbelief in Trump's Covid infection.

From this short excerpt, one can already see that this kind of discourse is usually not based on a mutual understanding and cooperation in a communicative act. One reason for that surely is this highly controversial figure of the US President, who triggers very opposing emotions and sentiments. A second reason why Twitter may be a good example for discord/disruptive discourse is that everyone who has a Twitter account can take part in this kind of discourse no matter which background the person has or which beliefs they hold. A third and final reason for its disruptive character may be the extremely ramified structure and the vast number of these tweets and their replies, i.e. no one is able to read each and every reply and make sense of it. Therefore, a lot of parallel discourses are started that on the surface belong to the original thread, but if the reader dives deeper into them they talk about very diverse and unrelated subject matters discourse at its limits. 


\subsection{Social media "ruin political discourse"?}

It is therefore not surprising that political commentators have claimed (provocatively?) "Social Media Are Ruining Political Discourse" (Bolter 2019). In the days of fake news and identity discourses, this is a huge political problem between interest groups. The net result of these communication problems is that each group ethnically stereotypes the other and in extreme cases no serious democratic discourse seems possible. Recent books on political discourses have even come up with the notion of 'corrupt discourses':

I discuss post-truth and bullshit, but I also incorporate into my terminological repertoire 'agnotology' - in short hand, the propagation of ignorance - and 'corrupt discourses' - which refers to attempts to cover up corrupt activity in and of themselves, along with the perversion of communication that occurs when politicians enter a spiral of mendacity in attempts to conceal wrongdoing. (Block 2019: 5)

From a linguistic perspective, the idea of text corruption has always been related to linguistic computing or to text-linguistics. Here the linguistic coherence mirrors the social coherence, or rather lack thereof:

Coherence is a defining characteristic of text. The principles of coherence are social in their origins and, being social, they point to meanings about 'social order'. The coherence of a text derives from the coherence of the social environment in which it is produced, or which it projects; it is realized by semiotic means. Nevertheless, the decision to select particular aspects of coherence, to shape coherence, to attribute coherence to a textual/semiotic entity or to deny it the status of coherence is always the act of a socially located maker and re-maker of a text. Power is involved in the making, recognition and attribution of coherence in a text. (Kress 2012: 36)

The recent development of digital communication has contributed enormously to the problem: "Notions of (in-)coherence are hugely more problematic and difficult: coherence and incoherence have become more visible with the ubiquity of screens and more difficult to establish with a move to horizontally organized power" (Kress 2012: 47). Figure 5 is an interesting example, because it shows that 'discord discourse' phenomena are not at all restricted to 'the West' and are frequent in a social media democracy like Nigeria (cf. also Opeibi 2018, Schmied 2018). In this example of limited discourse, the 'reply' to the 'revolution' is a birthday wish, contrasting national corruption and national pride, only the last phrase links the contrasting views by referring back to "those of you who never see". 


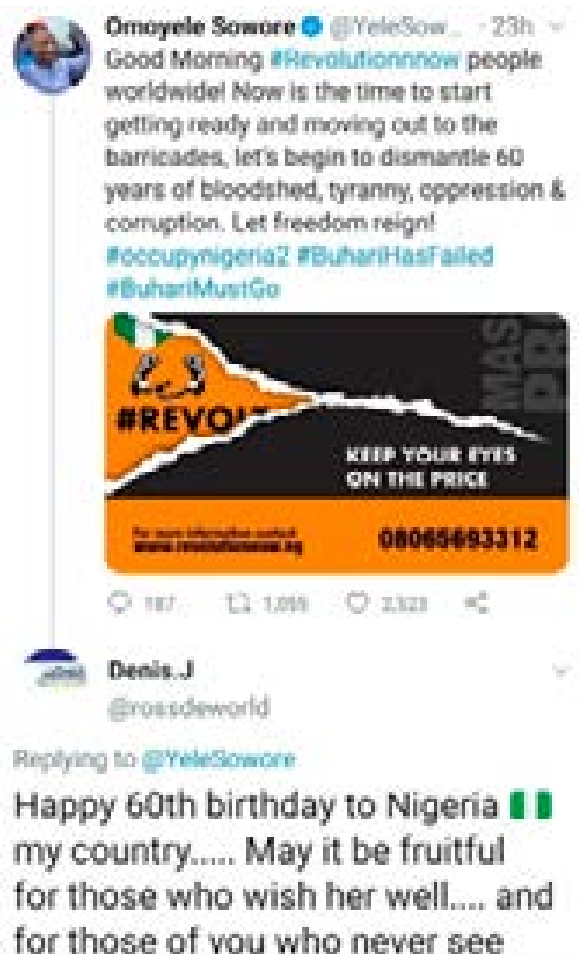

Figure 5: Political activism on Nigerian Twitter

\section{Perception of specific discourse usage in academic writing}

\subsection{Influence of social media on academic writing}

As social media usage is so common today among "millennials", the question is how this has affected writing styles in academic contexts. Rachel Cayley (2014) argues:

At a broad level, it seems clear to me that social media is beneficial for us as writers. When we write on social media, our natural ability to express ourselves may remind us that writing per se is not always the problem. Formal academic writing for an audience that seems both inscrutable and implacable can easily undermine our confidence. An opportunity to write more freely - with less anxiety about audience - can be a great reminder of our own writing ability. (Cayley 2014: n.p.) 
She identifies "three ways that social media writing can inform our development as writers": concision, tone, and nuance. While I am not convinced that "By writing things that are more direct or casual or polemical, we are better able to understand how such qualities may or may not operate within our more formal academic prose" (ibid.), I find interesting (in view of our previous discussion of interaction in social media) what she adds about disagreeing 'respectfully' in Twitter:

I find that Twitter is great for sharing things that I like, but not so good for those things about which I have significant reservations. Without room for caveats, we are left without an easy way to disagree respectfully. (ibid.)

It seems paradoxical that such negative, even chaotic discourse as above should induce well-planned, conventional discourse and wishful thinking that "writing for immediate consumption" requires "a more disciplined approach to writing". It remains arguable whether "greater awareness of the conventionality of writing will increase the chance that we will be able to find ways to work productively within those conventions" (ibid.).

\subsection{Conventionalisation of academic genres}

In recent years, academic writing classes have been introduced at European universities and metalanguage is taught explicitly on the local level (e.g. logical connectors) or on the global level (e.g. Introduction+Methodology+Results + Discussion $=\mathrm{IMRaD}$ structures for empirical studies). Of course, writers can always choose whether to follow disciplinary conventions or emphasise their individual identities. For academic success, it is important to know the conventions of academic genres, even for writers who consciously avoid using them, because they do not want to sound stereotypical or even robot-like (cf. 4.1 below). Strict conventions have advantages for the immediate discourse community, but they limit the accessibility for a wider audience or readership.

Example 4 illustrating German student writing taken from a discussion section in a BA thesis in Linguistics (ChemCorpus, Schmied 2015) shows that although local cohesion markers are inserted to help the reader to understand the coherence of the text, the argumentation is not as logically coherent as the rich academic vocabulary may suggest.

(4) The results have clearly shown that both learner groups encounter difficulties when producing relative clauses in their second language writing. As a matter of fact, 12 categories which were applicable to the analysis of both data sets were found. That leads to the assumption that, on average, both learner groups 
are confronted with the same problems. The assumption was proved via a chisquare test. This statistical investigation (cf. appendix for steps of calculation) of the overall results (cf. Figure $x$ ) showed that the differences across the error frequencies are not significant. Thus, the error frequencies are approximately equivalent. Generally, that could be due to the fact that both English and Italian belong to the Proto-Indo-European language family, however as pointed out in chapter 2.3.2, they belong to different subgroups, viz., Italic and Germanic. To my mind, that would give ground for an argumentation that since Italian and German belong to different subgroups, the 12 mutual categories were only found due to pure chance, with addition of three further categories that were exclusively found during the analysis of the Italian data. (BA09Ft_SK)

The four explicit logical connectors underlined are questionable: The first causal connector seems to suggest that if all cases could be assigned to only 12 categories, the difficulties/problems must be similar, but this is difficult to assess if we are not told explicitly (again) how many cases there were in this analysis and how many possible categories there are in the related literature. The second causal connector, thus, introduces a clause whose relationship with the previous clause is rather synonymous (not significant $=$ approximately equivalent), not causal. The contrastive connector however is interesting, as the contrast is not with the previous statement, the same family, but within the following, different subcategories of the language family. And then the hard argumentation seems to be thrown away by regressing to "pure chance"? And the final in addition looks like a small aside, but in fact points out a gross reader misunderstanding (only 12 categories above): there are only 12 mutual categories, but another three for the Italian exclusively.

\subsection{Eye-tracking as an indicator of reader 'thoughts' and problems of interaction}

This argumentation of how far the writer's text is accepted as logical by the reader also explains the recent focus in academic discourse on reader perception. Such pragmatic phenomena can be approached in terms of global coherence (cf. Unger 2006 and in 1 above), but also through a number of psycholinguistic experiments. The results of recordings of eye movement and non-movement during reading exercises (Pickering \& Traxler 1998, Roberts \& SiyanovaChanturia 2013) give us unique insights into readers' 'thoughts' today. Thus discourse problems on the readers' side become visible if they stop and 'think' or if they go back to find cohesive phenomena in the text to help them find the expected coherence, because they are stuck in the limits of discourse. 


\section{Humanoid teachers: Specific discourses with robots}

\subsection{Artificial intelligence approaches to text}

Today we have learnt to live with general models of talking robots from Amazon's Alexa to Google's Siri, but most of them are still confined to rudimentary order - execution interactions. The recent construction of Sophia (Makerspace 2017) is more challenging to our concepts of discourse, since the robots seem to do more than simply reproduce input ${ }^{2}$.

In our own professional capacity of writers, we are challenged by systems like Smart Compose. Seabrook (2019) tested the current AI options for creative writers and had a "creepy" experience:

(5) Finally, I crossed my Rubicon. The sentence itself was a pedestrian affair. Typing an e-mail to my son, I began "I am p-" and was about to write "pleased" when predictive text suggested "proud of you." I am proud of you. Wow, I don't say that enough. And clearly Smart Compose thinks that's what most fathers in my state say to their sons in e-mails. I hit Tab. No biggie.

And yet, sitting there at the keyboard, I could feel the uncanny valley prickling my neck. It wasn't that Smart Compose had guessed correctly where my thoughts were headed - in fact, it hadn't. The creepy thing was that the machine was more thoughtful than I was.

Read Predicted Text Generated by GPT-2 (including any quotes)

By that I mean, it seemed to want to distinguish my feelings from my thoughts. To put it another way, Smart Compose seemed to want to know me. (Text generation by Smart Compose (Seabrook 2019: 5))

The online version of the text in Example 5 is necessary, because the last paragraph after underlined "Read Predicted Text" is initially hidden and automatically generated.

If neural networks can predict our style for sentences ahead, the conventions of academic writing may become even more restricted - and the breaking of these conventions a sign of creativity and human professionalism. This is an interesting case where conventional genre-specific discourse may be provided by robots on the basis of a combination of disciplinary corpora and personal writings. Then professional discourse is really inspiring where it is not predictable too much. Thus, these developments in artificial intelligence may produce a contrast to the argumentation that conventions make the reader feel "at ease" - we are not, if we get the feeling that this is robot-like? 


\subsection{Constructing human-humanoid-human interaction with neural networks}

The use of neural networks for speech production has made enormous progress over the last few years (Rutherford et al. 2016). The interface of Google's Siri is publicly available and allows us to test how much input is necessary for a humanoid agent to produce an output that puts a human listener at ease with "the machine", either in accepting advice or in learning. Here language variation plays an important role. Of course, for native speakers features of their own language variety may create familiarity and lend credibility to the discourse partner. For non-native varieties this is much more difficult, not only because of the vast number of (non-standardized) varieties, but also because attitudes to different variants are not easy to predict. This does not only depend on linguistic variables (such as vowels, consonants, intonation contours, etc.), but also on personal and situational variables (like speed, pitch, emotion, etc.).

The following diagram (Figure 6) explains the four (reiterated) stages of a project that aims at generating non-native English output that is accepted as a basis for effective interaction by different groups of human discourse partners. In research stage 1, a database has to be compiled as input for an agent whose output aims at being a credible discourse partner. In stage 2, textual and (socio-) linguistic features can be modified to generate an output that is assessed positively in effective discourse. In stage 3, refined data-base and features are combined to create different personas (suggesting more partnership in some discourse cultures, more authority in others). Finally, in the last stage, the different personas are put to the test and suitable experiments should achieve the expected results, again in different discourse cultures. 


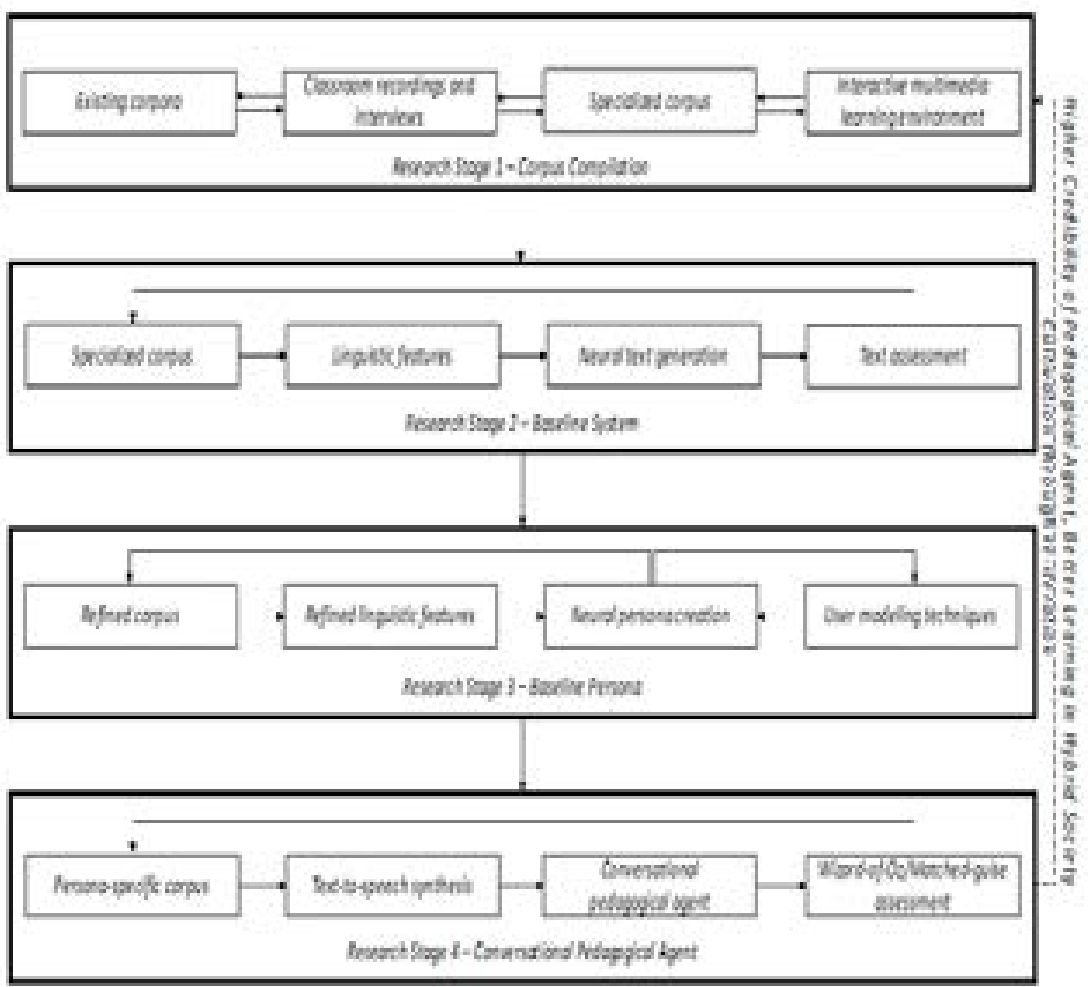

Figure 6: Iteration of four research stages of the humanoid agent as teacher (Schmied et al. fc.)

In the context of our argumentation on the limits of discourse, the project is interesting because we experiment through construing different discourses by changing the linguistic (and semiotic) input variables and measuring the subjective and objective efficiency of the interaction (details in Schmied et al. fc.). Linguistic input variables cover the whole range of linguistic features: pronunciation may vary from international standards to non-native familiar or unfamiliar features (e.g. consonants, vowels, intonation, speed, voice quality), lexicon may vary from general academic to discourse-community specific, grammar from simple to complex, etc. In any case we need the explicit indication of the willingness to interact well in the human input, the humanoid output and the human perception of this output. 


\subsection{Credibility for an effective humanoid teacher?}

If we aim for ideal discourse in the research procedure established in Figure 6 above, the input into the neural networks must be varied according to the overarching objectives: establishing positive discourse directed at cooperative interaction, credibility on the basis of acceptability of language and (perceived) personality and then measurable effective communication on the basis of content. Here a different limit of discourse can be noticed: Do we find an agent better when it is more conventional and stereotypical? Do some discord phenomena disturb the discourse and must they be eliminated through more and better input or do they make the humanoid agent more human and more credible and effective?

From a linguistic point of view, the old psychological concept of credibility (Hovland et al. 1953, Finn et al. 2009) is a good starting point to develop a more complex concept. It has text-linguistic (explicit) and sociolinguistic (attitudinal) components. Since we aim at constructing credibility, we reverse the traditional computational perspective that tried to evaluate the credibility of texts, usually WWW pages, by linguistic indicators among others. Whereas politicians (or the social media advisers) may define credibility as "offering reasonable grounds for being believed", the OED (s.v.) defines it as "the quality or state of being credible; capacity to be believed or believed in" and links it immediately to "credibility gap":

Originally U.S. a discrepancy between what is said or promised and what happens or is true; a disinclination to accept (esp. official) statements at face value.

Of course, this does not help much. We have to look up "credible" (s.v.):

1. a. Able to be believed in, justifying confidence; convincingly honest, principled, or authentic and often, as a corollary, accurate (passing into sense A. 1b); trustworthy, reliable.

b. Able to be believed; convincingly true or accurate.

c. Able to be believed in as effective or operational. Originally of a nuclear weapon: considered likely to be used.

From perspective of constructing a credible agent (in 4.2), it is the last sense that is most suitable. In the following OED senses, it is also interesting to see the frequency of the label 'erroneous' and the specification of credible, credulous and creditable: 
2. Ready, willing, or inclined to believe; credulous. Now commonly regarded as erroneous by usage writers.

3. Having or deserving credit or repute; creditable, reputable. Now only of an action, effort, or performance. Now commonly regarded as erroneous by usage writers.

Thus, the humanoid agent must receive human1 input that the neural network can use to produce an output that achieves crediblel $a$ and crediblel $b$ responses and thus a crediblelc discourse. Human 2 must be credible $2=$ credulous and the humanoid must be credible $3=$ creditable to achieve a fruitful (educational) discourse.

\section{Towards functional approaches to the limits of discourse: Explicit Intentionality cohesion}

In this contribution, I have discussed the limits of a traditional concept of discourse that can be perceived when the defining criterion of interaction is not met. Discord in discourse may be interesting and even 'human' in some situations, but it simply means more work for the reader in others. Of course, we cannot develop a comprehensive meta-theory on the basis of these examples, it may be enough to start integrating the new digital affordances into a cyberpragmatic approach (cf. Romero-Trillo 2016). I am convinced that all these elements can be integrated into the current systemic functional framework (Halliday \& Matthiessen 2014). The case study on the Hong Kong "umbrella movement" by Li et al. (2019) is an interesting attempt in this direction. In the final section, I would only like to recapitulate a few linguistic concepts that may be good starting points for discussing such crucial issues of our times.

\subsection{Communication and intentions}

In the widest context, modern linguists have been aware of problems in communication for over a hundred years. Since de Saussure, communication models have made it clear that effective communication is not just encoding and decoding of given information. For Posner (1993: 217), for instance, it involves

- beliefs,

- intentions to make others believe,

- intentions to modify one's own beliefs and

- intentions to make the partners act in specific ways straight away or later on. 
This wider world view is well-known as a gigantic issue for computer communication, but it is not enough. In our discourse perspective, it is important how much and how deep intentions are encoded in language, in the text. As it is no use to speculate about intentions, we need to focus on explicit signals of intention in discourse, as we have focused on cohesion signals to help readers to see coherence in text for almost 50 years. All these functional linguistic concepts are important elements in our discussion of coherent, interactive and constructive discourse.

\subsection{Intentionality in the philosophy of language}

In psychology, education and related disciplines, the concept of intentionality has been developed, but the meanings are often quite different and intentionality has been taken as the cognitive basis of intentions (Jankovic \& Ludwig 2018). In the philosophy of language, Searle (1983) made intentionality a central concept that was only slightly extended by Stalnaker (1999). Searle (1983: 1) defines: "Intentionality is that property of many mental states and events by which they are directed at or about or of objects and states of affairs in the world" and makes the distinction between intention and Intentionality clear at the very beginning:

Intending and intentions are just one form of Intentionality among others, they have no special status. The obvious pun on "Intentionality" and "intention" suggests that intentions in the ordinary sense have some special role in the theory of Intentionality; but on my account intending to do something is just one form of Intentionality along with belief, hope, fear, desire, and lots of others; ... In order to keep this distinction completely clear I will capitalize the technical sense of "Intentional" and "Intentionality". Intentionality is directedness; intending to do something is just one kind of Intentionality among others. (Searle 1983: 3)

For linguists, it may be tempting to overestimate the role of language, but Searle warns:

By explaining Intentionality in terms of language I do not mean to imply that Intentionality is essentially and necessarily linguistic... to attribute Intentionality to animals even though they do not have a language ... the relation of logical dependence is precisely the reverse. Language is derived from Intentionality and not conversely. (Searle 1983: 5)

Searle also contributes explicitly to our discussion of 'discord discourse' in his discussion of speech acts: 
The performance of the speech act is eo ipso an expression of the corresponding Intentional state; and, consequently, it is logically odd, though not selfcontradictory, to perform the speech act and deny the presence of the corresponding Intentional state. (Searle 1983: 9)

In his list of Intentional states (Searle 1983: 4), he includes among many others $^{3}$ "acceptance" and "respect", which are particularly important for our concept of cohesive discourse, which emphasises the linguistic indicators of and cues directed at interaction. For our discussion of discourse, language and speech acts are the basis:

But the members of the directive class of speech acts - orders, commands, requests, etc. - and the members of the commissive class - promises, vows, pledges, etc. - are not supposed to match an independently existing reality but rather are supposed to bring about changes in the world so that the world matches the propositional content of the speech act; and to the extent that they do or fail to do that, we do not say they are true or false but rather such things as that they are obeyed or disobeyed, fulfilled, complied with, kept or broken. I mark this distinction by saying that the assertive class has the word-to-world direction of fit and the commissive and directive classes have the world-to-word direction of fit. If the statement is not true, it is the statement which is at fault, not the world; if the order is disobeyed or the promise broken it is not the order or promise which is at fault, but the world in the person of the disobeyer of the order or the breaker of the promise. Intuitively we might say the idea of direction of fit is that of responsibility for fitting. (Searle 1983: 7)

The concept of intentionality needs at least two important additions for our argumentation. The central concept of direction-of-fit here corresponds with the pre-requisite of textual coherence in real successful discourse in the sense of Grice's coherence principle (originally 'the principle of conversational helpfulness', or of 'conversational benevolence'):

So I would like to be able to show that observation of the Cooperative Principle and maxims is reasonable (rational) along the following lines: that anyone who cares about the goals that are central to conversation/communication (such as giving and receiving information, influencing and being influenced by others) must be expected to have an interest, given suitable circumstances, in participation in talk exchanges that will be profitable only on the assumption that they are conducted in general accordance with the Cooperative Principle and the maxims. (Grice 1991 [1989]: 30). 
In their book Relevance, Sperber and Wilson (1995) develop an explicit theory of ostensive-inferential communication. This theory is designed to explain the inferential aspects of ostensive communication: how a hearer bridges the gap between sentence meaning and speaker's intended meaning. Sperber and Wilson see intention as a defining criterion of communication, they distinguish explicitly between informative and communicative intentions and they define the latter as "to make it mutually manifest to audience and communicator that the communicator has this informative intention" (ibid.: 61). Here again discord discourse would act against the conventional view that discourse implies cooperative, effective interaction.

\subsection{Explicit Intentionality cohesion to signal the intention to cooperate in discourse}

When Halliday and Hasan (1976) developed their concept of cohesion in text, as "linguistic means whereby texture is achieved" (ibid: 293), they did discuss "tight and loose texture" (ibid: 295-297), but they did not discuss "tight and loose discourse". None of their major cohesion categories (reference, substitution, ellipsis, conjunction, and even lexical cohesion) focus on discourse in our sense of interpersonal interaction between partners. Their small section "7.4.2. The texture of discourse" (ibid.: 326-7) states explicitly "Other forms of discourse are more obviously structured than conversation" (ibid.: 327) and then focuses on narratives, and even "literary forms, including 'strict' verse forms" (ibid), which does not help much in our argumentation here. The only phrase where Halliday and Hasan touch our problem of continuity in interactive discourse is this:

It is the continuity provided by the cohesion that enables the reader or listener to supply all the missing pieces, all the components of the picture which are not present in the text but are necessary to its interpretation. (ibid.: 299)

In the following brief discussion of comprehension problems, they always assume that the speaker/writer is willing to put enough effort into the text to make the decoding possible and easy. They focus on "how much can often be recovered simply from the presuppositions carried by the cohesive elements" (ibid.: 303). The concept of the 'texture of discourse' is not mentioned in Halliday and Matthiessen (2014), although it can, of course, be seen in the structural resources theme/rheme and given/new. But the problem of the limited effort in encoding or decoding a text to ensure continuity of the discourse is not addressed explicitly.

Thus, if we intend to be cooperative in political, academic and human-humanoid discourse without risking its limits, explicit cohesion markers can be used to 
signal intentionality in Searle's sense (above). All cohesive devices are welcome and may be used as explicitly as possible. This includes the reciprocal use of personal pronouns like $I / w e$ and you and the explicit repetition of lexical items apart from the formal signals like indentations and threads on Twitter, which are partly automatically provided since the problem is so obvious.

If we take the tweets in Figure 4 as examples, we could imagine polite, i.e. interacting, discourse using different types of cohesive signals (italicised) in the replies that take up elements in the main tweet explicitly:

The first reply by Kenyotta could state explicitly: Your pictures show that Trump sits too close to the driver and his secret service men ...

The second by Soph could refer back to the main tweet by repeating supporters, not replacing the reference by the insult idiots; it is good that she picks up the lexeme hospital directly and elaborates in this semantic field consistently by using sick, pain, and compassionate, so that this tweet has a better inner cohesion than most.

Kittyjo is apparently so full of religious language that she even capitalizes not only God, but also Great President and refers back lexically to supporters in the main tweet. Then, however, she addresses the team, probably not in the car, but in general? - a lost thread? Finally the negative and hate may refer to a general public or the tweets above. Despite the good inner cohesion, the relationship to the original tweet with the excursion photos is not clear at all, so that this tweet shows little cohesion to the utterances before and little cooperative intentionality; it intends to preach at other writers and not discuss with them.

measamnotabot maintains the link his to the noun President in the previous and main tweet, but the rest has no reference whatsoever to the main tweet, maybe the big car triggered the association rich and taxes?

Jack's reply has good cohesive signals directly to the tweet before by picking up taxes and a brief quote, but the formal link to the original tweet is not justified through cohesive signals.

ManaMana refers not only to the main tweet and another one, as formally indicated, but also to Kenyotta and Soph at the beginning of these replies, because of the lexical cohesion through health from the semantic field hospital/virus above.

\#MAGAKAG2020 selects the virus narratives focusing on the pros and cons of masks including the law enforcement (all prominent in US presidential discourses) and turns all this against the left ... Here the desire is obvious to "warm up" the annoying mask controversy that is hardly part of this discourse of the presidential drive-by. Many cohesive and argumentation links would be necessary - hardly imaginable in this heated twitter discourse. 
OLLIESMOM is similar to the first tweet because of the semantic link stunt - staged event. More explicit reference to "This whole drive-by outside the hospital", as in the main tweet may seem more work, but also polite, of course, since it is difficult to follow such links after a while, so making them very explicit should always help ...

In conclusion, we have to admit that when we look explicitly at the standard cohesive categories suggested by Halliday and Hasan (1976), we discover many pronominal and lexical signals that indicate continuity and coherence consciously or unconsciously. But finding the direct reference to the main and previous tweets is often hard work for the cooperative reader, so that we can argue whether the signals are clear enough or should be reconsidered consciously. Of course, readers will always find coherence if they are willing to work on it, but it is always polite by writers if they make the work easier for their readers or avoid misunderstandings. Both sides can indicate their intention to good discourse through mutual Intentionality in cohesive forms in adjacent phrases. The clear indication of Intentionality by using explicit and easy cohesive signals is a starting point for good interactive discourse that can be appreciated by partners in the ideal(ised) discourse we discuss here. Cohesive signals of intentionality from one utterance to the other are a minimum - maybe even more indicators can be found and should be used to overcome the limits of discourse today.

Evidently, the general suggestion to increase cohesive signals has been applied in many academic writing classes already. It has also been criticised as typical of non-native writing, because empirical studies have shown that many (often stereotypical and not logical) forms appear teaching-induced. In this context, we have to remind ourselves that there are no native speakers and no native norms for academic English and thus it remains a matter of convention and writer identity whether explicit cohesion markers are perceived as polite or annoying.

In general, from a linguistic perspective, all this looks like hard encoding work and even the modest suggestions for more explicit cohesion above may be seen as overdone, as including too much redundancy, but in digital communication and especially on social media it seems better to be more than explicit and include redundancy, possibly more than seems necessary at the moment of writing. Thus we become aware of the well-known observation that "A language is a series of redundancies" (Halliday \& Matthiessen 2014: 25; although they use it in a phonetic context!). 


\section{Conclusion}

If we try to reinterpret our limits of discourse in the three critical types of discourse outlined above (in 1.4), we take Searle's conditions of satisfaction as a starting point: "Every Intentional state with a direction of fit is a representation of its conditions of satisfaction" (Searle 1983: 13).

In political social media discourse, as I have tried to illustrate with examples from Twitter, the limits of discourse have become obvious to everyone. Opposed political parties have become enemies and talk (even shout) more at each other than with each other. Thus, cooperation is made impossible and even denied. This makes the essential interactive cooperative behaviour a defining criterion for effective discourse.

In subject-specific academic discourse, as visible in corpus data, conventions in the different academic genres have been established and must be adhered to more and more. Even if students are taught about cohesive devices (such as conjunctions) on the local level, global coherence is desirable to make supervisors or examiners feel 'at ease' and satisfied without distracting them with marked phrases that only 'stick out' because conventions are not met.

In humanoid-human discourse, anticipating human responses is crucial for establishing credibility as a basis for satisfactory cooperation between humanoid agents and humans. The focus on intentionality - attributing of intentions to the agent and construing credibility explicitly in language - depends, of course, on the conscious collaboration from the three research components of this project (cf. Figure 6 above, section 4.4): language input, computational deep-learning processing and measuring of learning output - but it is not a predictable, prefabricated, pre-programmed list of orders and set phrases, thus it expands the limits of discourse again if the non-human contribution increases.

Finally, the functional linguistic concept of cohesion can be useful to signal mutual effort to achieve effective, interactive, coherent discourse. It includes the concept of Intentionality not only as an abstract concept, but as a very concrete language feature, since cohesive features also serve as Intentionality markers across utterances. Just as coherence is easier to construe for the reader when the writer uses cohesive devices, Intentionality can be better assumed by the reader when the intention to cooperate in discourse is signalled in explicit Intentionality cohesion by the writer.

To conclude, although the mechanisms that are the basis of such limits of discourse are well-known from the related literature (e.g. Hasan's 1984 concept of 'cohesive harmony'), the limits of discourse have only come to the public discourse level through the recent digitalisation of discourses. However, our 
linguistic concept of discourse as Intentionality-based, coherent effective interaction has been supported recently by electrophysiological research. Stolk et al. (2014: 18184) conclude from their experiments with twenty-seven pairs of participants, who were given the task to communicate on a digital board game, that "effective communication arises only when a pair converges on a shared meaning". Thus, discourse is interaction, an act that is directed at initiating another cooperative act by the discourse partner. In a participatory ideal, discourse interaction brings satisfaction. Hopefully, only a minority draws satisfaction from showing the limits of discourse. Both types of Intentionality are possible, since a political response may be directed at maintaining or disrupting coherence in society. I hope to have shown that even here traditional concepts (like inferencing and presuppositions) can be supplemented by functional-pragmatic concepts (like cohesion and Intentionality) to reveal and analyse the dangers of discord in discourse as an indicator of discord in society and the limits of discourse in our times.

\section{Notes}

1 This contribution is based on a talk at the biannual Brno Conference on Linguistics Studies in English in September 2019 in Brno and I would like to thank the organisers for the invitation that allowed me to discuss some of the ideas for the first time in public. I also thank our departmental research group, esp. Dana Ebermann and Paul Onanuga, and my research partners in the Chemnitz Collaborative Research Centre CRC 1410 "Hybrid Societies: Humans Interacting with Embodied Technologies" and the D3 Project "Credibility through Language Varieties (CLaVa) in Conversational Pedagogical Agents" for continuous support and discussion, esp. Marina Ivanova, Matthias Hoffmann and Sven Albrecht.

The title "limits of discourse" can also be found online in a personal linguistic debate between Harris and Chomsky: https://samharris.org/the-limits-of-discourse/ (last accessed 10/09/19) from May 1, 2015: Sam Harris and Noam Chomsky attempt to have a conversation about the ethics of war, terrorism, state surveillance, and related topics - and fail. Though this is an interesting example of the limits of discourse in the political sphere, it is slightly different from the examples discussed here, because the opponents basically agree to disagree and no further discourse is necessary. This contribution is rather related to Burton-Roberts' (1989) "limits of debate", which focusses on presuppositions.

2 Of course, the "simple reproduction" of text can be similarly impressive, as demonstrated by the Chinese text-to-speech news presenter in Putonghua and (American) English (Cadell 2018). The robot becomes more interesting from our discourse perspective only when it starts to add text-specific 'emotions' to the interaction by tone, face or hand/arm variation. This again pushes the limits of 'discourse' in a 'hybrid society' of humans interacting with embodied technologies

3 The list also includes fear and anxiety, so that they seem both 'directed', but even linguistically fear from seems much more common than anxiety from/at, so that we may assume a difference in 'directedness'. In German, some academic users distinguish the near-synonyms Angst and Furcht, with the latter more directed or specific than the former (in addition to the stylistic difference that makes Furcht more formal). 


\section{References}

Block, D. (2019) Post-Truth and Political Discourse. Cham: Palgrave Macmillan.

Bolter, J. D. (2019) 'Social media are ruining political discourse. The endless flow of content doesn't need to make sense to create engagement.' The Atlantic. Online document. Retrieved on 02 October $2020<$ https://tinyurl.com/yya56vwj>.

Burton-Roberts, N. (1989) The Limits to Debate: A Revised Theory of Semantic Presupposition. Cambridge: Cambridge University Press.

Cadell, C. (2018) 'And now for something completely different: Chinese robot news readers.' Reuters Technology News. 9 November 2018. Online document. Retrieved on 02 October $2020<$ https://www.reuters.com/article/us-china-tech-aianchor/and-now-for-something-completely-different-chinese-robot-news-readersidUSKCN1NE19O $>$.

Cayley, R. (2014b) Social media and writing style explorations in writing style. A blog about academic writing. April 2 2014. Online document. Retrieved on 02 October $2020<\mathrm{https}$ ://explorationsofstyle.com/2014/04/02/social-media-and-writing-style/>.

Culpeper, J. (1996) 'Towards an anatomy of impoliteness.' Journal of Pragmatics 25, 349-367.

Darics, E. (ed.) (2015) Digital Business Discourse. London: Palgrave Macmillan.

Davies, M. (2016) Corpus of News on the Web (NOW): 10 billion words from 20 countries, updated every day. Online document. Retrieved on 02 October 2020. <https://www. english-corpora.org/now/>.

Discourse. (n.d.) Glossary of Multimodal Terms. Online document. Retrieved on 02 October $2020<\mathrm{https}$ ://multimodalityglossary.wordpress.com/discourse/>.

Dontcheva-Navratilova, O. (2009) Analysing Genre: The Colony Text of UNESCO Resolutions. Brno: Masaryk University.

Finn, A. N., Schrodt, P., Witt, P. L., Elledge, N., Jernberg, K. A. and Larson, L. M. (2009) 'A meta-analytical review of teacher credibility and its associations with teacher behaviors and student outcomes.' Communication Education 58, 516-537.

Gee, J. ([2009] 2015) Social Linguistics and Literacies: Ideology in Discourses. $5^{\text {th }}$ ed. London: Routledge.

Grice, P. (1991 [1989]) Studies in the Way of Words. Harvard University Press.

Halliday, M. A. K. and Hasan, R. (1976) Cohesion in English. London: Longman.

Halliday, M. A. K. and Matthiesen, C. (1999) Construing Experience Through Meaning: A Language-Based Approach to Cognition. London: Continuum.

Halliday, M. A. K. and Matthiessen, C. (2014) Halliday's Introduction to Functional Grammar. $4^{\text {th }}$ ed. London: Routledge.

Hardaker, C. (2017) 'Flaming and trolling.' In: Hoffmann, C.R. and Bublitz, W. (eds) Pragmatics of Social Media. Berlin: De Gruyter Mouton. 493-522.

Hasan, R. (1984) 'Coherence and cohesive harmony.' In: Flood, J. (ed.) Understanding Reading Comprehension: Cognition, Language, and the Structure of Prose. Newark, DE: International Reading Association. 181-219.

Herring, S. C. (ed.) (1996) Computer-Mediated Communication: Linguistic, Social and Cross-Cultural Perspectives. Amsterdam and Philadelphia: Benjamins.

Hovland, C. I., Janis, I. L. and Kelley, H. H. (1953) Communication and Persuasion: Psychological Studies of Opinion Change. New Haven, CT, US: Yale University Press. 
Lee, D. Y. W. and Swales, J. (2006) 'A corpus-based EAP course for NNS doctoral students: Moving from available specialised corpora to self-compiled corpora.' English for Specific Purposes 25(1), 56-75.

Li, E., Lui, P. and Fung, P. (2019) Systemic Functional Political Discourse Analysis: A Text-based Study. London: Routledge.

Jankovic, M. and Ludwig, K. (eds) (2018) The Routledge Handbook of Collective Intentionality. London: Routledge.

Jucker, A. H. and Taavitsainen, I. (2000) 'Diachronic speech acts: Insults from flyting to flaming.' Journal of Historical Pragmatics 1(1), 67-95.

Kress, G. (2012) 'Multimodal discourse analysis.' In: Gee, J. P. and Handford, M. (eds) The Routledge Handbook of Discourse Analysis. London: Routledge. 35-50.

Makerspace, T. (2017) 'Calling all robot bachelors: Sophia the robot might want to start a family'. 28 November 2017. Online document. Retrieved on 02 October $2020<\mathrm{http}: / /$ towsonmakerspace.blogspot.com/2017/11/calling-all-robot-bachelors-sophia.html>.

Opeibi, T. (2018) 'Gaining political capital through social media: A study of Akinwunmi Ambode's Twitter campaigns during the 2015 elections in Nigeria.' In: Opeibi, T. and Schmied, J. (eds) From the Virtual Sphere to Physical Space: Exploring Language Use in Nigerian Democracy (REAL Studies 13). Göttingen: Cuvillier, 1-29.

Pickering, M. J. and Traxler, M. J. (1998) 'Plausibility and recovery from garden paths: An eye-tracking study.' Journal of Experimental Psychology: Learning, Memory, and Cognition, 24(4), 940-961.

Posner, R. (1993) 'Believing, causing, intending: The basis for a hierarchy of sign concepts in the reconstruction of communication.' In: Jorna, R. J., van Heusden, B. and Posner, R. Signs, Search, and Communication: Semiotic Aspects of Artificial Intelligence. Berlin: De Gruyter. 215-270.

Renkema, J. and Schubert, C. (2018) Introduction to Discourse Studies. Amsterdam: John Benjamins.

Rutherford, A. T., Demberg, V. and Xue, N. (2016) 'Neural network models for implicit discourse relation classification in English and Chinese without surface features.' Retrieved on 02 October 2020. <https://arxiv.org/abs/1606.01990>.

Roberts, L. and Siyanova-Chanturia, A. (2013) 'Using eye-tracking to investigate topics in L2 acquisition and L2 processing.' Studies in Second Language Acquisition 35(2), 213-235.

Schmied, J. (2012) 'Social digital discourse: New challenges for corpus and sociolinguistics.' Topics in Linguistics: Approaches to Text and Discourse Analysis $10,43-56$.

Schmied, J. (2015) 'Academic writing in English in comparison: Linkers and adverbs in the ChemCorpus and comparable Data-bases.' In: Plo, R. and Pérez-Llantanda, C. (eds) English as a Scientific and Research Language in Europe. Berlin: De Gruyter Mouton, 159-184.

Schmied, J. (2017) 'Linguistic Approaches to Credibility in Academic and Media Texts.' In: J. Schmied and I. van der Bom (eds) Working with Media Texts: Deconstructing and Constructing Crises in Europe. Göttingen: Cuvillier, 1-16.

Schmied, J. (2018) 'Web discourses in Nigeria's democracy: How new Digital Humanities methodologies can be used to follow national language practices.' In: Opeibi, T. and Schmied, J. From the Virtual Sphere to Physical Space: Exploring Language Use in Nigerian Democracy (REAL Studies 13). Göttingen: Cuvillier. 31-41.

Schmied, J., Hoffmann, M. and Albrecht, S. (fc.) 'Linguistic Credibility as a key issue in the communication between humans and humanoids in a Hybrid Society.' 
Seabrook, J. (2019) 'The next word. Where will predictive text take us?' The New Yorker. 14 October 2019. Online document. Retrieved on 02 October $2020<$ https://tinyurl. $\mathrm{com} / \mathrm{y} 2 \mathrm{~g} 5 \mathrm{nbeu}>$.

Searle, J. (1983) Intentionality. An Essay in the Philosophy of Mind. Cambridge: Cambridge University Press.

Sperber, D. and Wilson, D. (1995) Relevance: Communication and Cognition. Hoboken: Wiley-Blackwell.

Stalnaker, R. C. (1999) Context and Content. Essays on Intentionality in Speech and Thought. Oxford: Oxford University Press.

Stolk, A., Noordzij, M. L., Verhagen, L., Volman, I., Schoffelen, J. M., Oostenveld, R., Hagoort, P. and Toni, I. (2014) 'Cerebral coherence between communicators marks the emergence of meaning.' Proceedings of the National Academy of Sciences, 111(51), 18183-18188.

Romero-Trillo, J. (ed.) (2016) Yearbook of Corpus Linguistics and Pragmatics 2016: Global Implications for Society and Education in the Networked Age. Berlin: Springer.

Unger, C. (2006) Genre, Relevance and Global Coherence. The Pragmatics of Discourse Type. London: Palgrave Macmillan.

Josef Schmied has held the Chair of English Language \& Linguistics at Chemnitz University of Technology since April 1993. His main research interests are in Language \& Culture (sociolinguistics, English in Africa and SE Asia, Academic English) and in Language \& Computers (corpus-linguistics, e-learning, www English). His current research projects focus on the use of internet data in linguistic analysis, disciplinary conventions of academic writing and humanoid-human interaction in non-native Englishes.

Address: Josef Schmied, Chemnitz University of Technology, English Language and Linguistics, 09107 Chemnitz, Germany. [e-mail: josef.schmied@phil.tuchemnitz] 